\title{
PerCursos
}

\section{Un pueblo y una clave para filosofar}

\begin{abstract}
Resumen
Tiempos inéditos para reflexionar y preguntarnos ¿Será posible sospechar que hay un pensamiento único? ¿Ayudará la situación a vislumbrar una forma diferente de estar en el mundo? Para romper los parámetros de la modernidad y posmodernidad necesitamos situarnos en otro lugar, Dussel lo describe como una nueva manera de construir el mundo, la transmodernidad. Los caminos para reconocer y vivir otros mundos son desconocidos y diversos, presentaremos uno existente desde hace varios siglos, cuando no era América y no existía la colonización, imposición que intentó silenciar a pueblos originarios. Pretender una actitud descolonizadora invita a experimentar una inserción - inculturación o una indigenización; son posibilidades para superar el paradigma racional dominante e ingresar al 'ayxa sk'ujol, ser entre los humanos "con corazón” y "no entre los cerebrales". Un posible acceso a este saber ancestral, requiere de una clave en contexto mediante una lengua desconocida y desconsiderada. Seguiremos a Lenkersdorf en su libro Filosofar en clave tojolabal y también nos ayudaremos con algunos comunicados de pueblos mayas en lucha contemporánea de resistencia. Esta lengua maya contiene el sonido "tik", como desinencia y es la clave que a nosotros los occidentales nos desconcierta, confunde o de plano no entendemos.
\end{abstract}

Palabras clave: Indigenización. Filosofía indígena. Filosofía decolonial.

\author{
Nancy Lamenza Sholl da Silva \\ Psicología social / estudios latino- \\ americanos, Universidad \\ Nacional Autónoma de México, \\ (UNAM); profesora adjunta, \\ Universidade Federal \\ Fluminense.. \\ Brasil \\ nancylamenza@gmail.com
}

\section{José Luis Victorio Cervantes} Psicología / salud mental y atención psicosocial, Escola Nacional de Saúde Pública Sergio Arouca (Fiocruz); psicólogo, proyecto: Rede de psicólogos do

Centro de Atendimento aos

Refugiados.

Brasil

c0985rj@gmail.com

\section{Para citar este artigo:}

SILVA, Nancy Lamenza Sholl da; CERVANTES, José Luis Victorio. Un pueblo y una clave para filosofar.

PerCursos, Florianópolis, v. 22, n.48, p. 37 - 60, jan./abr. 2021.

DOI: $10.5965 / 19847246224872021037$

http://dx.doi.org/10.5965/1984724622482021037

\footnotetext{
${ }^{1}$ Para profundizar sobre el tema, ver: LENKERSDORF, Carlos. Filosofar en clave tojolabal. Ciudad de México: Miguel Porrúa, 2002.
} 


\section{A people and a key to philosophize}

\begin{abstract}
Unprecedent times to reflect and ponder: Is it possible to claim an unified way of thinking? Will these circumstances help us catch a glimpse of another way to be in the world? To tear modern and post-modern parameters we need to view things from a different perspective. Dussel describes this as a new way of creating the world, transmodernity. The means to recognize and live other worlds are diverse and unknown, we will show one that existed centuries ago, when we weren't America yet and colonization, an imposition that tried to silence native peoples, didn't exist. By aiming at a decolonizing atitute, we invite ourselves to experiment an "insertion or interculturation" or an "indigenization"; they are possibilities to surpass the dominant racional paradigm and acess the 'ayxa sk'ujol, to be between humans "with heart" and "not between cerebrals"2. A possible way to acess this ancestral knowledge requires a contextual key upon an unknown and disregarded language. We'll use Lenkersdorf in his book "Filosofar en clave tojolabal" as well as some papers written by mayan people on the contemporary resistance's struggle. The Mayan language has the sound "tik" as sufix and it's the key that makes we, westerns, baffled, confused or is beyond our understanding.
\end{abstract}

Keywords: Indigenization. Indigenous philosophy. Decolonial philosophy.

\section{Um povo e uma chave para filosofar}

\section{Resumo}

Tempos inéditos para refletir e nos perguntar: É possível suspeitar que exista um único pensamento? A situação ajudará a imaginar uma forma diferente de estar no mundo? Para quebrar os parâmetros da modernidade e da pós-modernidade, precisamos nos colocar em outro lugar, Dussel o descreve como uma nova forma de construir o mundo, a transmodernidade. Os caminhos para reconhecer e viver outros mundos são desconhecidos e diversos, apresentaremos um que já existia há vários séculos, quando não era a América e não existia a colonização, uma imposição que tentou silenciar os povos originários. Ter a pretensão de uma atitude descolonizadora convida-nos a experimentar uma inserção ou inculturação ou uma indigenização; são possibilidades de superar o paradigma racional dominante e acessar o 'ayxa sk'ujol, de ser entre os humanos "com coração" e "não entre os cerebrais"3. Um possível acesso a esse conhecimento ancestral requer uma chave contextualizada através de uma linguagem desconhecida e desconsiderada. Seguiremos Lenkersdorf em seu livro "Filosofar en clave Tojolabal" e também usaremos alguns comunicados dos povos maias na luta de resistência contemporânea. Essa língua maia contém o som "tik", como uma desinência e é a chave que a nós ocidentais desconcerta, confunde ou não entendemos.

Palavras-chave: Indigenização. Filosofia indígena. Filosofia decolonial

\footnotetext{
${ }^{2}$ For more details, see: LENKERSDORF, Carlos. Filosofar en clave tojolabal. Ciudad de México: Miguel Porrúa, 2002.

3 Para aprofundar o assunto, ver: LENKERSDORF, Carlos. Filosofar en clave tojolabal. Ciudad de México: Miguel Porrúa, 2002.
} 
El tema considerado por la Revista "Los Estudios Decoloniales Centrados en las Filosofías Indígenas Amerindias", parece contener la idea de que existen otros mundos, por lo que habrá que desentrañar ese aspecto implícito mediante el ¿quién pregunta? y ¿quién pretende escribir respecto al tema? Desde las directivas propuestas y enmarcadas, infiero que, es sólo una preocupación por registrar que existe un saber de pueblos originarios, en su experiencia confrontante y su existir resistente. Hacer algo distinto a un registro implicaría una actitud con la cual podamos decir “Hermanos: No morirá la flor de la palabra. Podrá morir el rostro oculto de quien la nombra hoy, pero la palabra que vino desde el fondo de la historia y de la tierra ya no podrá ser arrancada por la soberbia del poder" (Cuarta... 1996, sin paginación) en el ahora de los días actuales. Es imperativo asumir el tema más allá de las normas académicas. Pues los saberes que los pueblos originarios han acumulado hasta el presente, son de otro orden, de otra dinámica temporal, explicitado de algún modo en lo que el espíritu zapatista ${ }^{4}$ comunica con en el “iya basta!”. Un ya basta conformado en siglos, una respuesta al intento de destruirlos y transformarlos en ciudadanos de un país, de un Estado Nación. Esto dentro de un proceso de recolonización, hoy neoliberal, y que una vez más intenta despojarlos de sus territorios, por ellos “concebidos como los espacios geográfico-simbólicos de su reproducción como entidades socio-étnicas colectivas," (LÓPEZ Y RIVAS, 2018, sin paginación). Pueblos originarios que sobreviven desde la conquista y se perpetúan hasta nuestros días. ¿Cómo se articula el tema escogido por la revista, sin reproducir una sumisión a la mecánica que profiere la estructura de la institución académica? ¿Podríamos considerar el cuestionamiento del mundo no indígena como herramienta fundamental para la constitución de una descolonización de los procesos de producción y legitimación de los conocimientos de forma equitativa?

¿Cuándo la academia propone este tema se quiere saber lo que enfrentan y significa ser estos pueblos o convierten a los pueblos en un nuevo especialismo acrítico? Creo que es importante que esta cuestión surja como un planteamiento propio de la

\footnotetext{
${ }^{4}$ Movimiento de pueblos originarios mayas en el sureste mexicano que buscan reivindicar derechos básicos. Con el nombre de Ejercito Zapatista de liberación Nacional, se manifiestan públicamente el primero de enero de 1994, declarando la guerra al gobierno mexicano, hoy continúan como un movimiento autónomo y asediados desde entonces por los gobiernos en turno.
} 
universidad, pensarse para descolonizarse, pero ¿esto será posible con las estructuras vigentes? Es un reto difícil, pues a pesar de nuevos conceptos y propuestas teóricas decoloniales, postcolonialistas y anticolonialista, esto no garantiza la construcción efectiva de una pluridiversidad.

En este caso el llamado que se hace, lo podemos considerar como una invitación a promover una actitud crítica hacia el modo en el que la estructura dominante coloca la validez del discurso universal y su reproducción. Con esto es importante resaltar que el paradigma vigente es una atrofia que impide ver y experimentar que existe, como ya mencionamos, un afuera, otros mundos posibles. El tema propuesto tendría que propiciar un proceso para experimentar con quien vive y produce esa cultura y filosofar, la de los pueblos originarios. O sea, asegurar una relación que coexista con "la construcción de otras epistemologías nativas" (XAKRIABÁ, 2020, sin paginación). Pues siempre existe el riesgo de la apropiación, objetificación y la reformulación de nuevas jerarquías entre los saberes.

Hablar, escribir sobre este tema dentro de los paradigmas académicos occidentales, pretendiendo una actitud diferente, nos colocaría en un lugar de conflicto, pues con muy buena intención, podremos no estar percibiendo que estamos promoviendo prácticamente la distancia y la ruptura con esos pueblos originarios a través del especialísimo acrítico y del teoricismo hipertrofiado5 ${ }^{5}$. Como una de las características del paradigma occidental, el del lugar para “entender” y que nos autoriza después, a ser referencia para hablar con autoridad de estos temas. La comprensión atrofiada del paradigma occidental nos coloca, desde nuestra entrada a este mundo, pues al ser amantados y respirar todos los días los marcos conceptuales que la delimitan en una estructura que obviamente intenta ser universal. Esto nos impide la posibilidad de otras versiones, de otras narrativas existentes, fuera de nuestros conocidos parámetros racionales. Estos marcos se construyen con conceptos como: civilización, progreso, desarrollo, mercado, propiedad privada, emprendedores, etc. Que se van complejizando y terminan por encerrarnos, impidiéndonos entender y experimentar un más allá del

\footnotetext{
5 Para profundizar sobre el tema, ver: RODRIGUES, Heliana. Perigos e promessas de encontro entre grupalismo e historiografia na formação de psicólogos. Rebeirão Preto, 1998. Disponible en: http://pepsic.bvsalud.org/pdf/tp/v6n1/v6n1a04.pdf. Acceso en: 10 oct. 2010.
} 
único mundo concebido. Vivimos el mundo nuestro de cada día, con ese orden establecido y conjugado mediante las diversas instituciones que conforman hoy nuestro sistema y orden establecido, en el que se evidencian ejes ideológicos como la división de clase, el patriarcado, el racismo, por mencionar algunos, tejidos como estructuras conformadoras. En donde cada institución, de nuestro orden establecido, nos enseña a reproducir sutilmente un mismo mundo, provocando el juego de la no salida, estimulando una ceguera a posibles vías de escape, incapacitándonos para poder descubrir versiones de mundos coexistentes.

Estos ejes nos enseñan a percibir que lo que no es homogéneo, es un extranjero y muy probablemente peligroso, como todo aquel que no pertenezca a la narrativa del único verso, al que históricamente el proceso ha propuesto como la modernidad y por la neocolonización. Todo este proceso tergiversa la intensión de las luchas de independencia, que en teoría ponían fin al proceso colonizador. Esta versión única de un proyecto civilizatorio basado en la modernidad se perpetua a través de enmarañados de instituciones que dan vida al sistema capitalista neoliberal en los Estados Nación. Consideramos que este contexto nos exige trabajar con tensiones, conflictos, ambigüedades, etc.

En el área académica, que es la que nos corresponde ahora, tendremos que ser lo suficientemente hábiles para crear el conflicto, y de este modo, evitar ser cómplices de los epistemicidios. ¿Y cómo lograr esto? Espero descubramos algunas pistas, al terminar este artículo, sorprendiéndonos con lo desconocido y preguntando al caminar.

Los “Mayas-zapatistas"

Cuando los "mayas-zapatistas" en Chiapas, como parte de una organización de pueblos originarios, se agruparon como el Ejercito Zapatista de Liberación Nacional $(E Z L N)^{6}$, dando inicio a un proceso autonómico de consecuencias históricas a nivel planetario e intentan comunicarse con occidente diciendo:

\footnotetext{
${ }^{6}$ Movimiento social surgido públicamente en primero de enero de 1994, en el estado de Chiapas, México “... nuestra bandera lleva las letras «EZLN», EJÉRCITO ZAPATISTA DE LIBERACIÓN NACIONAL, y con ella iremos a los combates siempre.” Primera declaración de la selva Lacandona.
} 
Para ellos, nuestras historias son mitos, nuestras doctrinas son leyendas, nuestra ciencia es magia, nuestras creencias son supersticiones, nuestro arte es artesanía, nuestros juegos, danzas y vestidos son folklore, nuestro gobierno es anarquía, nuestra lengua es dialecto, nuestro amor es pecado y bajeza, nuestro andar es arrastrarse, nuestro tamaño es pequeño, nuestro físico es feo, nuestro modo es incomprensible.

Para mirarnos, ellos miran hacia atrás y hacia abajo.

Para ellos, reconocernos es reconocerse ellos superiores.

Para ellos, vernos es vernos sometidos.

Para ellos, mirarnos es ordenarnos.

Para ellos, darnos un lugar es señalarnos la tumba, la cárcel, el olvido.

Ellos, los que están arriba de quienes abajo estamos.

Ellos ayer nos «civilizaron» y hoy quieren «modernizarnos».

Ellos nos dicen que el mundo de ellos es mejor.

Que debemos dejar nuestra tierra, nuestra casa, nuestra historia.

Que debemos venir a la tierra de ellos y vivir bajo ella.

Que debemos vivir en la casa de ellos y servir en ella.

Que debemos ser parte de su historia y morir en ella.

Esto nos ofrecen: bajo su pie vivir, su voluntad obedecer, en el olvido morir.

Para los indígenas en México hoy sólo hay dos opciones: o resistir o «modernizarse» (Palabras... 2001, sin paginación)

Los que se consideran occidentales en este comunicado ¿A quién escuchan y desde dónde? ¿Cómo miden la profundidad de estas palabras? Acaso escuchan con una actitud que les permita saberse diferentes, no iguales y se preguntan ¿desde qué lugar nos hablan? Algunas respuestas pueden darse de manera general: desde el lugar de la opresión crónica. Entre tanto, quién habla desde allá son aquellos que intentan comunicarse con interlocutores ¿Desde que lado de la línea "abismal”7 se encuentran los interlocutores?

Entonces que actitud necesitamos para poder leer el mundo de los pueblos originarios, en este caso el de los "mayas-zapatistas", para poder entender su cultura, su filosofar como una propuesta de descolonización. Ellos pretenden ser escuchados, seguramente sus comunicados fueron engendrados en su lengua materna, después traducidos de su lengua, del tojolabal o tzeltal al castellano. Se dice que una traducción

\footnotetext{
7 Para profundizar sobre el tema ver: SANTOS, Boaventura. MENESES, Maria. Epistemologia do Sul. São Paulo: Cortez Editora, 2010.
} 
puede ser una traición. Luego la relación entre mundos pasa por la lengua y en este sentido hay que considerar que una lengua es también un filosofar.

La lógica maya del tiempo y por lo tanto la gramática de sus verbos, es la de las espirales del caracol, en las cuales el presente todavía se nutre de la memoria para digerir el pasado y reciclarlo en un futuro creador pero homogéneo, con la dinámica caracolera del tiempo. El caracol aspira todo en sus espirales interiores, y también se abre a exteriores imprevistos pero con productos siempre reciclados y por tanto renovados. (AUBRY, 2003, sin paginación)

Ellos saben bien que son colocados, por quienes los hoyen, desde este lado, en el lugar de la "equivocación”. Y al respecto nos dicen: “Por que mandan nuestros primeros que los de abajo enmienden lo que los de arriba equivocan... pero, hasta ahora, los que siempre se equivocan son ellos y nosotros somos la equivocación y quién la paga." (Palabras... 2001, sin paginación). Esta es la experiencia de la imposición de los unos sobre los otros, cada lado de la línea abismal, ¿sabemos de qué lado estamos, les comprendamos o no? Pero ellos continúan caminando y desde su implicación emprendieron de nuevo el camino de la construcción de una nueva autonomía, ahora por la vía de los hechos. Se han reorganizado para este propósito, escuchando sus saberes y sumando factores que condicen con su emancipación. Desde el lugar de la escucha y el dialogo podemos juntos caminar y descubrir su saber como un filosofar, uno que necesita ser comprendido con la ayuda de una "clave", desde un "Filosofar en clave tojolabal", uno que se rige por parámetros muy otros y que es posible descubrir al acercarnos y, como diría Casaldáliga, según nos cuenta Quintana, acercarnos de una manera que posibilite ver el mundo "a la altura del pueblo [originario]" (QUINTANA, 2020, sin paginación), sin la arrogancia occidental del sabedor y así preguntar, intentar aprender de ellos, abiertos a otros referentes nuevos, desconocidos y nunca experimentados en occidente.

Carlos Lenkersdorf, en su libro Filosofar en clave tojolabal, nos muestra la riqueza que muestra la lengua tojolabal y tzeltal, la grandeza y diferencia de este conocimiento, 
esta es una experiencia de vida con estructuras tan diferentes, que por ejemplo, ellos nunca se han pensado como dueños individuales de alguna cosa.

Para la filosofía occidental, el pensamiento racional es un referente indispensable para poder argumentar con criterios lógicos y colocando en un nivel menor lo que carezca de estructuras racionales, sistémicas, y considerados como totalmente arbitrarios, inconsecuentes, y por lo tanto, sin ninguna validez como conocimiento sólido y científico.

Considerando que traducir desde una lengua a otra, cuando se tienen los mismos referentes, como lenguas indoeuropeas, como es el caso de las lenguas latinas, no dificultará la comprensión de la traducción, pues existen equivalentes, aunque se llega a decir que traducir es empobrecer el texto. Imaginemos entonces, intentar traducir lenguas que tengan otros orígenes y por lo tanto otras cosmovisiones, como dice Lenkersdof (2002, p. 7) “realidades ni siquiera soñadas”.

Resulta que desde occidente será imposible comprender este filosofar, sin intentar algún movimiento en el paradigma dominante, la experiencia de un mundo donde:

Todo vive porque tiene corazón... [y entonces es posible hablar] con plantas, animales y cosas, hechas por los hombres. [Donde hay] conceptos abstractos que difícilmente se entendían en español. Se formaba la mayoría de las palabras, y de familia de palabras, a partir de raíces de no más de tres letras. $Y$, finalmente, encontraba conceptos y giros lingüísticos sin equivalencia o correspondencia en castellano. Por eso hablo no solo de otro mundo, sino del germinar de una nueva idea. (LENKERSDORF, 2002, p. 7-8).

En la formación del movimiento zapatista confluyeron una diversidad de acontecimientos, como fuente y concreción del mismo, que a lo largo de los años les permitieron esta actualización de lucha y organización que son hoy, esto demuestra que, estos pueblos originarios, no están parados en el tiempo como víctimas de los “equívocos" de los de arriba. Su tiempo representado por "la curvatura del caracol es aquella de las espirales imprevisibles del espacio-tiempo, y no la circunferencia necesariamente repetitiva de la geometría griega." (URBY, 2003, sin paginación). Precisamente uno de esos elementos de una riqueza desconocida, es la que nos es 
presentada y evidenciada, a través de vivenciar al pueblo tojolabal en su lengua, y así ser revelado el saber practicado por estos pueblos originarios, por el lingüista Lenkersdorf en su libro Filosofía en clave tojolabal.

El trabajo de Lenkersdorf es argumentado con la tesis de que una lengua es la que se revela en su práctica mediante

las cosmovisiones [que] están relacionadas con el comportamiento de la gente, porque éste no contradice las cosmovisiones, y así se dan las cosmovivencias que, a su vez, se hacen explicitas en el filosofar ético y en el campo de la justicia. En resumidas cuentas, la presencia de la cosmovisión en todas las bifurcaciones de las ramas de una lengua, conforma de maneras diferentes el filosofar de una nación o cultura determinada. (LENKERSDORF, 2002, p. 12).

Hacer presente al movimiento zapatista, conformado por grupos de pueblos originarios mayas como tzotziles, tzeltales, choles, tojolabales y otros, y a la vez colocarnos al mismo nivel de escucha y experiencia, según palabras de Casaldáliga, en el artículo de Quintana, será la estrategia que junto con la clave de su filosofar, nos ayudará a descubrir en algunos de sus comunicados, precisamente, ese filosofar que está detrás. Esperando que esta acción nos ayude a comprender lo que implica movernos de nuestra arraigada versión paradigmática, a través de una experiencia que nos ayude a sumergirnos en una cosmovivencia. Que a su vez nos ayude a "sentipensar", el cómo se da y mantiene la lucha de estos pueblos en la contemporaneidad:

[... ] y vimos, hermanos, que era DIGNIDAD todo lo que teníamos, y vimos que era grande la vergüenza de haberla olvidado, y vimos que era buena la DIGNIDAD para que los hombres fueran otra vez hombres, y volvió la dignidad a habitar en nuestro corazón, y fuimos nuevos todavía, y los muertos, nuestros muertos, vieron que éramos nuevos todavía y nos llamaron otra vez, a la dignidad, a la lucha. (Al CONSEJO... 1994, sin paginación)

\footnotetext{
${ }^{8}$ Para profundizar sobre el tema ver: Artículo: MORAES, María. Sentipensar bajo la mirada autopoiética o cómo reencantar creativamente la educación. Barcelona, 2001. Disponible en: http://www.ub.edu/sentipensar/pdf/sentipensartweb.pdf. Acceso en: 14 ago. 2020.
} 
En este texto que explícitamente nos señala la experiencia de lo que significa la actualización de su DIGNIDAD, desde la ética y justicia de su filosofar y el compromiso que esto adquiere. Vibrar en la sintonía de este filosofar será difícil sin la cosmovivencia, la experimentación de la cotidianidad, el dejarse tocar en la convivencia, el estar entre ellos y asumirse como dignos de vivir. Lejos del mundo de la fragmentación que impone el paradigma occidental. En donde el territorio, el cuerpo, la organización, la vida no están disociados. El solo ejercicio racional, como mero dato informativo se queda corto, es muy poco fértil para situarnos espacialmente dentro de esos referentes, para habitar ese otro mundo coexistente, en su territorio. Por eso asumimos la importancia de la experiencia narrada por Lenkersdorf, cuando por primera vez se vive inmerso en el territorio maya tojolabal: “Al toparme con ellos me di cuenta de que no entendía ni una sola palabra. Solamente se me grabó un sonido que me acompañaba y sigue acompañándome hasta la fecha... sembró la inquietud en mi corazón..." (LENKERSDORF, 2002, p. 7).

Es importante rescatar en el escrito de Lenkersdorf el aspecto experiencial, el “sentipensar”, más allá del entendimiento fraccionado, “me di cuenta”, "se me grabó”, "sembró la inquietud en mi corazón" o sea lo que ya habíamos nombrado como cosmovivencia. Hay una relación en donde está presente su mundo de forma entera, como la principal diferencia respecto de nuestro paradigma occidental dominante, que se caracteriza por esa racionalidad que no necesita sentir. La convivencia ayuda a descubrir que necesitamos más que sustantivos, es la experiencia que hace real el movimiento de contacto con otras realidades.

Lenkersdorf (2002) visitó por primera vez en los Altos de Chiapas a estos pueblos mayas, en 1972, invitado para ayudar en un trabajo de traducciones. Llegó después de un largo viaje por caminos de terracería al poblado tzeltal de Bachajon, al norte de Ocosingo, llegó un día en el que se realizaba una asamblea del pueblo tzeltal. Entraron a la reunión y todo era extraño, diferente, pues no conocían a nadie y no entendían nada de lo que se hablaba. Parecía ser una reunión animada, todas las personas participaban, eran unas cuarenta o cincuenta personas. De toda la diversidad de elementos nuevos que ahí concurrían, lo que más le llamaba la atención, era que en esa lengua desconocida se podía 
reconocer un sonido característico que se repetía constantemente, todos hablaban al mismo tiempo y claramente percibimos que no había nadie que dirigiera aquella reunión. El sonido que se repetía constantemente y por todos los participantes, era una silaba o palabra que con toda claridad distinguíamos, era un: "lalalatik, -lalalatik, -lalalatik, con la voz ascendente y el acento en la última sílaba [... ¿ ¿qué puede significar ese -tik, -tik, -tik? [...] debía ser algo de mucha importancia [... ¿ ¿Por cuál razón se producía la reiteración?” (LENKERSDORF, 2002, p. 24). En esa primera experiencia, se podía percibir que ese -tik misterioso, era el vehículo por el cual se desarrollaba el intercambio de ideas y proposiciones de los participantes. Posteriormente "pensamos que, en este -tik repetido, el lenguaje tiene un fundamento alrededor del cual los hablantes, mujeres y hombres, están tejiendo sus ideas y aportes." (LENKERSDORF, 2002, p. 25). Como lingüista sabía que en ningún otro idioma conocido en occidente era posible observar esta característica. Menciona que esta experiencia le hizo recordar que:

[...] en el gnosticismo, en tiempos del helenismo, con la palabra y la experiencia-clave de "estar en el exilio" [...] los gnósticos se entendían $[\ldots]$, fuera de su patria, [...] de su hogar, [...] del lugar al que pertenecían. A esto nos referimos al hablar de una experiencia-clave. (LENKERSDORF, 2002, p. 25).

Finalmente al terminar la reunión les fue informado que el sonido -tik es una desinencia, que significa NOSOTROS.

¿A dónde llevó esta característica, en la lengua tzeltal escuchada por Lenkersdorf? El siguiente párrafo nos puede dar la pista:

No hay certezas, pero quizás es momento de recuperar y potenciar la forma de lagramática de la dignidad insurrecta. Aquel lenguaje/hablado/caminado de los pueblos indígenas del CNI organizados y en resistencia - quienes estando con la Madre Tierra saben escuchar su dolor, no sólo porque vienen resistiendo una Guerra de exterminio, y por tanto su re-accionar de forma urgente se arremolina en proponer la reconciliación como pueblos, más resistencia, más 
colectividad, eliminar de sus caminos partidos y programas de gobierno, construir escuelas, medios de comunicación y clínicas autónomas, fortalecer culturas, formas de autoabastecimiento y autogobiernos, genera encuentros, comisiones de trabajo, etc. Esta es nuestra única confianza ante la dinámica de matanza del sistema capitalista y su forma de gobierno despótico. $Y$ aún más significativo porque dicho compromiso contiene en sí misma una iniciativa post-patriarcal. "El llamado por la Vida del CNI y el EZLN ¿Una iniciativa pospatriarcal?” (LUNA, 2017, sin paginación)

A partir de la experiencia de Lenkersdorf, somos invitados a cambiar de lugar, a colocarnos fuera de los parámetros de la filosofía occidental del Yo como fundamento individual, para adentrarnos al mundo maya desde una de las lenguas que nos llevan a los principios del Filosofar en clave tojolabal. Esta clave la encontró en ese sonido percibido desde el inicio, en el primer contacto con ese pueblo, la clave es el -tik, ahí está contenido algo que podemos traducir como "NOSOTROS", que "Aparece, reaparece y brilla en los ámbitos menos esperados, desde el caos social hasta el tiempo cíclico, el sistema numérico y la poesía" (LENKERSDORF, 2002, p. 12).

Al relacionar estas dos últimas citas, tal vez podamos apreciar lo que Gutiérrez dice como "dignidad insurrecta" con el referente de esa clave. La nosotridad que en su filosofar se constituye desde estructuras que no consideran la individualidad como premisa, para ser dueños de algo. Para occidente esto es primacía y en nombre de ello se les somete, se les coloniza. Donde su ética y justicia se vive como, lo que Gutiérrez llama de más colectividad o lo que genera encuentros. Si pudiéramos escuchar en lengua tojolabal el mensaje dirigido al Consejo Guerrerense 500 años de Resistencia Indígena, distinguiríamos muy probablemente, con facilidad, esa clave, el -tik "NOSÓTRICO" reflejado en el comunicado.

Al situarnos en ese otro lugar, podríamos ver en el tejido y articulación de esa lucha de resistencia, el sentido de su lucha por construir su autonomía, desde los elementos que impregnan su cultura. Acercarnos a algunos de los inúmeros 
pronunciamientos que estos pueblos nos envían desde el inicio de su levantamiento público, en enero de 1994 y hasta el día de hoy, nos ayudaran a encontrar más pistas.

Al seguir la experiencia de esos pueblos originarios en el largo caminar de estos años, desde el levantamiento armado en 1994 hasta los días de hoy, y que ellos han estado dispuestos a compartir, podríamos entender la solidez y congruencia de lo construido hasta ahora. Más la ceguera y sordidez del paradigma occidental continua con el intento de su destrucción, porque no asumen y piensan como lo que para occidente es el llamado progreso y desarrollo, que a propósito, solo se efectiva para unos cuantos, casi seguro que quien lee esto no está incluido.

Una vez más, para tener la capacidad de descubrir desde ese otro lugar necesitamos recordar que tenemos que movernos, salir del espacio conocido e ir, convivir, hacer un espacio para ese otro que demanda ser experimentado, como sugiere Lenkersdorf (2002, p. 27), una inserción o inculturación, para Xakribá sería la indigenización9. Dejar de ver desde vitrinas racionales, para ir hacia... y dejar de ser investigadores distantes, tenemos que convertirnos en aprendices y así promover la coexistencia y de facto la descolonización. Este aprendizaje implica salir de la racionalidad característica de occidente, el pienso y luego existo cartesiano, para dejarse tocar por una experiencia, como ya mencionamos antes, desde una sensibilidad que nos ayude a abandonar la racionalidad individual, necesitamos lo que ellos llaman 'ayxa sk'ujol, que traducido del tojolabal al castellano, sería algo así como “tener corazón ya”. Lo que "Predomina [...] entre los humanos "con corazón" y no entre los cerebrales" (LENKERSDORF, 2002, p. 28). Una analogía a esta manera de estar en el mundo es la que menciona Celso Sanchez con la palabra terrexistir: "todo existir es interdependiente de la tierra, de otros seres y nada existe por sí mismo" (NOGUERA, 2017, p. 121).

\footnotetext{
${ }^{9}$ Concepto a ser enriquecido con la propuesta que hace Célia Xakribá: Otro concepto con el que dialogamos es el de indigenización. Ese es un concepto ya conocido entre los antropólogos e historiadores, acuñado por el estadounidense Marshall Sahlins [...] Sahlins presenta la categoría de indigenización buscando diferenciarlo del concepto de aculturación - esto nos interesa, sobretodo, como forma de contraponer la imagen preconcebida de que nosotros, pueblos indígenas, seríamos "aculturados". (XAKRIABÁ, 2020, sin paginación, traducción nuestra).
} 
Aludiendo a las palabras de los zapatistas al inicio de este artículo, cuando mencionan la percepción, de inferioridad, que tiene occidente de ellos, como pueblos mayas; surge la cuestión de que, si los que están del lado contrario a ellos, no aceptan que los parámetros son otros, no van a poder coexistir con lo que ellos nos muestran, realidades inexistentes en occidente, un orden diferente, que es colectivo y no jerárquico, que dialoga con lo que está vivo:

Así los «Caracoles» serán como puertas para entrarse a las comunidades y para que las comunidades salgan; como ventanas para vernos dentro y para que veamos fuera; como bocinas para sacar lejos nuestra palabra y para escuchar la del que lejos está. Pero sobre todo, para recordarnos que debemos velar y estar pendientes de la cabalidad de los mundos que pueblan el mundo. (CHIAPAS... 2003a, sin paginación).

Somos invitados por Lenkersdof, a considerar que una característica muy importante en estos pueblos, es que al parecer desde antes de los tiempos coloniales y durante, en su organización socio-política “[... ] no había capital ni autoridad principal alguna, sino que se vivía ya conforme a principios organizativos horizontales [... ] y que se hacen presentes en los tiempos actuales." (LENKERSDORF, 2002, p. 19).

De ahí que podamos percibir que los zapatistas se comunican desde un NOSOTROS, y desde su percepción de la coexistencia de otros mundos.

Comprender lo que significa la desinencia -tik, provoca que nos demos cuenta que nuestro correspondiente Yo es un pronombre autónomo. O sea, "YO que se encierra en sí mismo, que se aísla de todo lo demás, para obtener una seguridad firme e indubitable de algo que existe y que, precisamente, es el YO pensante." (LENKERSDORF, 2002, p. 31). Para los tzeltales y tojolabales lo que importa es su incorporación "NOSÓTRICA" como entidad cualitativamente distinta, una unidad organísmica, como la describe Lenkersdorf. Aquí no existe la búsqueda de afirmar un interés individual, pues se vive como un NOSOTROS. "La separación del todo, en cambio, hace al individuo marchitarse y perderse" (LENKERSDORF, 2002, p. 32). Al respecto tenemos esta citación al inicio del comunicado zapatista del 24 de febrero de 2001 
Cuentan nuestros viejos más viejos que los más primeros de estas tierras vieron que los dzules, los poderosos, llegaron a enseñarnos el miedo, vinieron a marchitar las flores y, para que la flor del poder viviese, dañaron y sorbieron la flor de(I) nosotros. (EN SAN... 2001, sin paginación).

Occidente trajo la preeminencia del YO, dañando, creando un desarraigo a la flor de experimentarse como colectivo, que dificulta enormemente la posibilidad de experimentar el "NOSOTROS vivencial" enseñando el miedo y marchitando las flores borraron a través del silencio, la mordaza la cultura de su saber colectivo. El "marchitar las flores" de la cita anterior, es un acto directo en contra de estos pueblos mayas, y muy probablemente como una agresión directa, destruyendo su grafía, su "alfabeto glífico, no de letras sino logogramas y afijos silábicos con más de mil signos," (URBY, 2003, sin paginación) y convirtiendo así sus lenguas en ágrafas. Es un sometimiento o la eliminación de la diversidad, y sin siquiera experimentarlas. Porque el ser occidental solo sabe que "piensa luego existe".

En los primeros encuentros entre los pueblos mayas y los no indígenas que constituyeron el EZLN, el NOSOTROS comunitario fue desconcertante. Solamente después de experimentar la indigenización ${ }^{10}$ se logró un real encuentro entre diferentes. O sea, por estar totalmente inseridos, fue que pudieron asumirse en una cosmovivencia en ese otro mundo posible, y entonces dialogaron. En este contexto es que podemos comprender la rebeldía indígena. Una rebeldía que no se configura como una respuesta al opresor y sus connotaciones, sino una afirmación de su dignidad, como podemos percibir en el comunicado abajo:

[... En la madrugada del día primero del primer mes del año de 1994, un ejército de gigantes, es decir, de indígenas rebeldes, bajó a las ciudades para con su paso sacudir el mundo.

Apenas unos días después, con la sangre de nuestros caídos aún fresca en las calles citadinas, nos dimos cuenta de que los de afuera no nos veían.

Acostumbrados a mirar desde arriba a los indígenas, no alzaban la mirada para mirarnos.

\footnotetext{
10 "formas de vida, los conocimientos y la identidad de diversos grupos indígenas asentados en Los Altos y en otras regiones de Chiapas." (LÓPEZ, 2017, p. 51)
} 
Acostumbrados a vernos humillados, su corazón no comprendía nuestra digna rebeldía.

Su mirada se había detenido en el único mestizo que vio con pasamontañas, es decir, que no miraron.

Nuestros jefes y jefas dijeron entonces:

"Sólo lo ven lo pequeño que son, hagamos a alguien tan pequeño como ellos, que a él lo vean y por él nos vean"

Empezó así una compleja maniobra de distracción, un truco de magia terrible y maravillosa, una maliciosa jugada del corazón indígena que somos, la sabiduría indígena desafiaba a la modernidad en uno de sus bastiones: los medios de comunicación.

Empezó entonces la construcción del personaje llamado "Marcos" [...]

Marcos un día tenía los ojos azules, otro día los tenía verdes, o cafés, o miel, o negros, todo dependiendo de quién hiciera la entrevista y tomara la foto. Así fue reserva en equipos de futbol profesional, empleado en tiendas departamentales, chofer, filósofo, cineasta, y los etcéteras que pueden encontrar en los medios de paga de esos calendarios y en diversas geografías. Había un Marcos para cada ocasión, es decir, para cada entrevista. Y no fue fácil, créanme, no había entonces Wikipedia [...]

Es nuestra convicción y nuestra práctica que para rebelarse y luchar no son necesarios ni líderes ni caudillos ni mesías ni salvadores. Para luchar sólo se necesitan un poco de vergüenza, un tanto de dignidad y mucha organización. [...]

[... ] No habrá funerales, ni honores, ni estatuas, ni museos, ni premios, ni nada de lo que el sistema hace para promover el culto al individuo y para menospreciar al colectivo. (ENTRE... 2014, sin paginación).

Cuando son vistos desde la negación, ellos se hacen visibles desde su organización que es colectiva, que no necesita de reconocimientos individuales, pero como estrategia de interlocución con occidente, crea un personaje, se relacionan mediante su propio lenguaje. Su saber propone un caminar preguntando y de beneficio comunitario. Ese caminar preguntando tiene frutos en la reconstrucción de su autonomía.

El NOSOTROS, obviamente proporciona a los autores tojolabales la firmeza y seguridad que Descartes buscaba en la interioridad del pensamiento. Por ello, ambas, firmeza y seguridad, en el contexto tojolabal, no dependen del saber firme y seguro. No están ubicadas en la razón o el pensamiento, sino en el actuar conforme a la vocación tojolabal de comportarse nosótricamente; es decir, el "así viviremos en comunidad" [...] "sólo así nos ayudaremos" (LENKERSDORF, 2002, p. 49). 
Con la congruencia en ese actuar realizan su lucha de resistencia y construcción de su caminar y ahora practicada desde una autonomía que es un iya basta! Y que podemos ser testigos de su construcción hasta hoy. Perdura y es vida que reexiste, porque está hecha de la creatividad conjunta, comunitaria del nosotros; "la curvatura del caracol [...] aquella de los espirales imprevisibles del espacio-tiempo," (URBY, 2003, sin paginación). No ha sido fácil en todos estos años, pero ha sido una experiencia liberadora. Una creatividad que surge de la diversidad que genera la vida. $Y$ esta se genera desde un ensayo y error, desde un preguntar para caminar. En su caminar por la liberación, ellos saben que occidente ordinariamente es caritativo:

[...] No es nuestra carencia la que nos duele, es el ver en otros lo que otros no ven, la misma orfandad de libertad y democracia, la misma falta de justicia. (...) De lo que nuestra gente sacó de beneficio en esta guerra, guardo un ejemplo de <<ayuda humanitaria>> para los indígenas chiapanecos, llegado hace unas semanas: un zapato de tacón de aguja, color rosa, de importación del número 6 y $1 / 2 \ldots$ sin su par. La llevo siempre en mi mochila para recordarme a mí mismo, [...] lo que somos para el país después del primero de enero: una cenicienta. (...) Esta buena gente que, sinceramente, nos manda un zapato rosa, de tacón de aguja, del 6 y 1/2, de importación, sin su par... pensando que, pobres como estamos, aceptamos cualquier cosa, caridad y limosna. ¿Cómo decirle a toda esa gente buena que no, que ya no queremos seguir viviendo la vergüenza de México? En esa parte que hay que maquillar que no afee al resto. No, ya no queremos seguir viviendo así. >>"

Eso fue en abril de 1994. Entonces pensamos que era cuestión de tiempo, que la gente iba a entender que los indígenas zapatistas eran dignos y que buscaban no limosnas sino respeto. [...] y en los <<Aguascalientes >> se amontonan computadoras que no sirven, medicinas caducas, ropa extravagante (para nosotros) que ni para las obras de teatro [...] Y siguen llegando cosas así, como si esa gente dijera <<pobrecitos, están muy necesitados, seguro que cualquier cosa les sirve y a mí esto me está estorbando >.

No sólo, hay una limosna más sofisticada. Es la que practican algunas ONG's y organismos internacionales. Consiste, a grosos modos, en que ellos deciden qué es lo que necesitan las comunidades y, sin consultarlas siquiera, imponen no sólo determinados proyectos, también los tiempos 
y formas de su concreción. Imaginen la desesperación de una comunidad que necesita agua potable y a la que le endilgan una biblioteca, la que requiere de una escuela para los niños y le dan un curso de herbolaria.

[...] Con no pocas personas hemos insistido en que la resistencia de las comunidades zapatistas no es para provocar lástima, sino respeto. Acá, ahora, la pobreza es un arma que ha sido elegida por nuestros pueblos para dos cosas: para mostrar que no es asistencialismo lo que buscamos, y para demostrar, con el propio ejemplo, que es posible gobernar y gobernarse sin el parásito que se dice gobernante. [...]

El apoyo que demandamos es para la construcción de una pequeña parte de ese mundo donde quepan todos los mundos. Es, pues, un apoyo político, no una limosna. [... ] (CHIAPAS... 2003b, sin paginación).

Nuestro comportamiento inamovible vertical y asistencialista es evidenciado en lo que ellos dieron por nombrar "el complejo de Cenicienta". ¿Y cuáles han sido las consecuencias de este aprendizaje? En nueve años, de 1994 hasta 2003, se organizaron e hicieron visible para occidente lo que ellos llamaron los "Caracoles", formas de autogestión de sus municipios autónomos en ese caminar.

Otro ejemplo relacionado al "Complejo de Cenicienta" es la experiencia de la investigadora Mariana Mora Bayo, que generó un trabajo titulado "Producción de conocimientos en el terreno de la autonomía". La investigadora al intentar iniciar su trabajo de investigación creyó que era suficiente presentar sus ideas a fin de que fueran aprobadas. Pero, para las comunidades zapatistas no era la investigadora quien debería delimitar el objetivo de la investigación, sino la propia comunidad. Mariana tuvo que cuestionar sus presupuestos de lo que sería una investigadora y una investigación fuera de los parámetros científicos occidentales europeos. Ella tuvo que inserirse en la lógica comunitaria de los caracoles. La investigación tuvo que ser una investigación de la comunidad. Esto implicó que su propuesta de investigación, se discutiera en asamblea municipal, de la cual formaban parte de 35 comunidades del municipio autónomo y, le informaran las decisiones tomadas para su investigación. Esta intervención dio como resultado que lo que presentó como proyecto de investigación, fuera modificado por decisiones comunitarias. Estas acciones hacen evidente que los pueblos originarios, están 
poniendo en práctica el cómo superar “[... ] el positivismo y el mito de la neutralidad universal, [... ] bajo nuevos conceptos éticos y de compromiso social." (BAYO, 2011, p. 81). La investigadora, nos cuenta que, asumió referentes metodológicas feministas y de investigación-acción. Estos referentes permitieron evidenciar que “[...] la investigación es un dialogo lleno de desigualdades, complicidades y de resistencias" (BAYO, 2011, p. 82). Pero la participación activa de las comunidades al convertirse en actores históricos que interpelan al investigador, desde una ancestralidad, permitieron que esta fuera parte del mismo proceso autonómico y este a su vez tema de debate político.

Esta es la evidencia de como los pueblos originarios mayas en Chiapas, al asumir su saber ancestral, retoman su filosofar y es posible identificar a quienes desde occidente dialogan con ese saber y salen del lugar monoversal. $Y$ juntos como diferentes, más al mismo nivel, comienzan a construir un lugar en donde es posible reconocer diferencias y posibilidades.

El primer proyecto de investigación de Mariana es equivalente al zapato rosa de tacón. Un ejemplo donde podemos detectar la sutilidad de la pretensión en la investigación occidental, que en realidad reproduce el exterminio o la asimilación e integración desde las estructuras vigentes.

\section{El lenguaje como filosofía.}

Revisaremos, del libro de Carlos Lenkersdorf (2002), algunos textos en lengua tojolabal o tzeltal, en donde es posible detectar la palabra clave NOSOTROS y como esta se repite, pero al hacer la traducción al español, es posible notar que no todos los -tik corresponden a los nosotros del castellano. Presentaremos algunas partes de un poema y este no tiene autoría, pues como ya mencionamos, el NOSOTROS no necesitamos de datos individuales. Comprender esta dinámica significa saber que no son los creadores, sino los que transmiten el poema, que se convierten en sembradores del mensaje para las comunidades. Así hay un presente actualizado en el poema: "NUESTRAS CANCIONES" (LENKERSDORF, 2002, p. 43). Consideramos importante resaltar que la investigación de 
Mariana al ser trasladada a la lógica de la comunidad también cumple la misma función de ser sembradora del mensaje para las comunidades.

Aquí hay otra sutileza del epistemicidio practicado por occidente, pues habría que entender, cuáles han sido sus estrategias y alcances de apagamiento de una cultura milenaria. La alfabetización que se hacía para estos pueblos, en las pocas escuelas existentes, se hacía en castellano, su lengua no era considerada. Esto reafirmaba el mensaje de que la escritura era considerada conocimiento privilegiado de lenguas civilizadas y no “dialectos”, ellos sabían que:

"Los pueblos indios de Chiapas no tenían escritura, por ello carecían de civilización. [...] se les decía que su "dialecto" no servía, porque no tenía escritura ni podía describirse por tener sonidos para los cuales no había letras. Los tojolabales lo creían, porque no veían nada escrito en su lengua." (LENKERSDORF, 2002, p. 44).

Como ya mencionamos, los conquistadores se habían encargado de destruir su alfabeto glífico, el de logogramas y afijos silábicos y, el sometimiento al que fueron relegados impidió que este se mantuviera. Fue hasta esta época, en 1975 que se confrontaron con el redescubrimiento de la posibilidad de su comunicación escrita. Este descubrimiento de la alfabetización en su idioma los coloca en una reflexión autocrítica. Hasta ese momento decían "No nos respetan, ni nos aprecian pero nosotros, nada decimos." (LENKERSDORF, 2002, p. 44). Y los poetas escriben:

[...] mixa sb' ejuk wa xyalawe

mi meranuk jel wa sna`awe`

porke lajan `ay jpensartik

yujx mi xkolta jb'ajtikik

ja`yuj wa xb'ob' yujile` i $[\ldots]$

( LENKERSDORF, 2002, p. 41-42, grifo del autor). ya no es justo lo que dicen ni es verdad que son muy sabios porque pensar sabemos todos pero falta es la NUESTRA porque no nos ayudamos 
En el movimiento zapatista, es posible observar la presencia de la idiosincrasia del NOSOTROS para organizarse en un despertar de lucha con DIGNIDAD.

"Porque es la lengua NUESTRA, un producto nosótrico, el que nos da fuerza, nos anima y reta:

[... ] ja`yuj t'ilan `oj jtzom jb'ajtik

`oj kal jb'ajtik jas `oj jk'ultik

jas yuj wa xyixtala`anotik

mi sb'ejuk ja jach' ‘aytik [...]

(LENKERSDORF, 2002, p. 41,45, grifo del autor).
Es necesario que nos juntemos

y platiquemos lo que haremos por qué nos toca ser explotados

y no es justo cómo nos tratan

Por ahora, este artículo solo pretende dar indicios a partir de una clave "tik", la riqueza y complejidad de una cultura desconocida por ser negada. Las comunidades zapatistas y la construcción de su autonomía bajo los parámetros de este filosofar es ya una experiencia de 36 años, que camina a contracorriente, que sigue siendo para muchos incomprendida y atacada.

Para finalizar es importante comprender que esta lucha representa un doble deseo: “[...] Oposición y reinvención [...] de los procesos complementares, pues la oposición por sí misma no basta. No se puede simplemente oponerse [...] después que alguien se haya opuesto y resistido, existe la necesidad de hacerse de nuevo" (KILOMBA, 2019, p. 28-29, traducción nuestra).

\section{Referências}

AL CONSEJO Guerrerense 500 Años de Resistencia Indígena: que nuestros corazones junten sus pasos. [S.I.], 1 feb. 1994. Disponible en: http://enlacezapatista.ezln.org.mx/1994/02/01/al-consejo-500-anos-de-resistenciaindigena-que-nuestros-corazones-junten-sus-pasos/ Acceso en: 25 ago. 2020.

ARISTEGUI noticias. Ciudad de México, 20 ago. 2020. Disponible en: https://aristeguinoticias.com/2008/mexico/2020-la-pandemia-con-enrique-dussel-el-virus- 
y-la-transmodernidad/?fbclid=IwAR3E1wJWSDoT2YOBGh6mjCyucooqHiomvSo4HwG4B34elbOhUUzPXmvios. Acceso en: 20 ago. 2020.

AUBRY, Andrés. Los caracoles zapatistas (Tema y variaciones) La Jornada, Ciudad de México, 24 nov. 2003. Suplemento Ojarasca 79. Disponible en:

https://www.jornada.com.mx/2003/11/24/oja-caracoles.html. Acceso en: 28 sept. 2020.

BAYO, Mariana. Producción de conocimientos en el terreno de la autonomía, La investigación como tema del debate político. In. BARONNET, Bruno; BAYO, Mariana; STAHLER-SHOLK, Richard (org.) Luchas "muy otras" Zapatismo y autonomía en las comunidades indígenas de Chiapas. Ciudad de México: CIESAS, UAMX y UACH, 2011, p. 79 - 110. Disponible en: http://zapatismoyautonomia.wordpress.com/. Acceso en: 17 sep. 2020.

CUARTA declaración de la selva Lacandona. [S.I.], 1 ene. 1996. Disponible en: https://enlacezapatista.ezln.org.mx/1996/01/01/cuarta-declaracion-de-la-selva-lacandona/. Acceso en: 17 ago. 2020.

CHIAPAS: la treceava estela. La historia del sostenedor del cielo. [S.I.], 21 jul. $2003 a$. Disponible en: https://enlacezapatista.ezln.org.mx/2003/07/21/chiapas-la-treceava-estelaprimera-parte-un-caracol/. Acceso en: 2 sep. 2020.

CHIAPAS: la treceava estela: segunda parte: una muerte. [S.I.], 21 jul. 2003b. Disponible en: http://enlacezapatista.ezln.org.mx/2003/07/21/chiapas-la-treceava-estela-segundaparte-una-muerte/. Acceso en: 21 ago. 2020.

Chiapas: la treceava estela. Tercera parte: un nombre. La historia del sostenedor del cielo. [S.I.], 21 jul. 2003C. Disponible en: https://enlacezapatista.ezln.org.mx/2003/07/21/chiapasla-treceava-estela-tercera-parte-un-nombre-la-historia-del-sostenedor-del-cielo/. Acceso en: 21 ago. 2020.

EN SAN Cristóbal de las Casa, comienza la Marcha de la Dignidad Indígena, la Marcha del color de la tierra. [S.I.], 24 feb. 2001. Disponible en:

http://enlacezapatista.ezln.org.mx/2001/02/24/en-san-cristobal-de-las-casas-comienza-lamarcha-de-la-dignidad-indigena-la-marcha-del-color-de-la-tierra/. Acceso en: 24 ago. 2020.

ENTRE la luz y la sombra, IV Un holograma cambiante y a modo. Lo que no será. [S.I.], 25 may. 2014. Disponible en: http://enlacezapatista.ezln.org.mx/2014/05/25/entre-la-luz-y-lasombra/. Acceso en: 24 ago. 2020.

KILOMBA, Grada. Memorias da plantação: episódios de racismo cotidiano. Rio de Janeiro: Cobogó, 2019. 
LA marcha del color de la tierra. [S.I.], 24 feb. 2001. Disponible en:

http://enlacezapatista.ezln.org.mx/2001/02/24/en-san-cristobal-de-las-casas-comienza-lamarcha-de-la-dignidad-indigena-la-marcha-del-color-de-la-tierra/ . Acceso en: 22 ago. 2020.

LENKERSDORF, Carlos. Filosofar en clave tojolabal. Ciudad de México: Miguel Ángel Porrúa, 2002.

LÓPEZ, Efrén. Lucha, resistencia y educación: una experiencia organizativa del pueblo tsotsil en el sureste mexicano. Ciudad de México: Itaca, 2017. Disponible en: https://www.academia.edu/40442242/Lucha_resistencia_y_educaci\%C3\%B3n. Acceso 30 sept. 2020.

LÓPEZ Y RIVAS, Gilberto. ¿Cumplir los Acuerdos de San Andrés? La Jornada, ciudad de México, 7 sept. 2018. Opinión. Disponible en: La Jornada: ¿Cumplir los Acuerdos de San Andrés?. Acceso en: 10 ago. 2020.

LUNA, Diana. El Ilamado por la Vida del CNI y el EZLN ¿Una iniciativa pospatriarcal?. Rebelión, [s.l.], 6 ene. 2017. Disponible en: https://rebelion.org/una-iniciativapospatriarcal/ Acceso en: 2 sep. 2020.

MORAES, María. Sentipensar bajo la mirada autopoiética o cómo reencantar creativamente la educación. Barcelona, 2001. Disponible en:

http://www.ub.edu/sentipensar/pdf/sentipensartweb.pdf. Acceso en: 14 ago. 2020.

NOGUERA, Renato. Consumo, logo existo: capitalismo, subjetividade e racismo. In: ARREGUY, Marília. COELHO, Marcelo. CABRAL, Sandra (org.). Racismo, capitalismo e subjetividade. Niterói: ADUFF, 2017. p. 103-125.

PALABRAS del EZLN el día 9 de marzo de 2001 en Milpa Alta, D.F., hoy ciudad de México. [S.l.], 2001. Disponible en: https://enlacezapatista.ezln.org.mx/2001/03/og/en-milpa-altaellos-quieren-que-nuestras-derrotas-sean-perpetuas/. Acceso en: 17 ago. 2020.

PRIMERA declaración de la selva Lacandona. [S.I.], 1 ene. 1994. Disponible en: http://enlacezapatista.ezln.org.mx/1994/01/01/primera-declaracion-de-la-selva-lacandona/. Acceso en: 22 ago. 2020.

QUINTANA, Victor. Las causas de don Pedro Casaldáliga. La Jornada, ciudad de México, 14 ago. 2020. Disponible en: https://www.jornada.com.mx/2020/08/14/opinion/018a1pol Acceso en: 20 ago. 2020.

SANTOS, Boaventura. MENESES, Maria. Epistemologia do Sul. São Paulo: Cortez Editora, 2010. 
XAKRIABÁ, Célia. Amansar o giz. Piseagrama, Belo Horizonte, n. 14, p. 110 - 117, 2020. Disponible en: https://piseagrama.org/amansar-o-giz/. Acceso en: 14 sept. 2020.

Recebido em: 19/10/2020 Aprovado em: 18/03/2021

Universidade do Estado de Santa Catarina - UDESC Centro de Ciências Humanas e da Educação - FAED

PerCursos

Volume 22 - Número 48 - Ano 2021 revistapercursos@gmail.com 